\title{
Medical Care Disruptions During the First Six- Months of the COVID19 Pandemic: The Experience of Older Breast Cancer Survivors
}

\section{Asma Dilawari ( $\sim$ Asma.A.Dilawari@medstar.net)}

Medstar Washington Hospital Center https://orcid.org/0000-0001-5706-9138

\section{Kelly Rentscher}

UCLA: University of California Los Angeles

\section{Wanting Zhai}

Georgetown University

\section{Tim A Ahles}

Memorial Sloan-Kettering Cancer Center Inpatient Hospital and Main Campus: Memorial Sloan Kettering Cancer Center

Jaeil Ahn

Georgetown University

\section{Traci Bethea}

Georgetown Lombardi Comprehensive Cancer Center

Judith E Carroll

UCLA: University of California Los Angeles

Harvey Cohen

Duke University

\section{Deena Graham}

Hackensack Hospital Association: Hackensack University Medical Center

\section{Heather Jim}

Moffitt Cancer Center

\section{Brenna C McDonald}

Indiana University School of Medicine

\section{Zev Nakamura}

University of North Carolina at Chapel Hill School of Medicine

\section{Sunita Patel}

City of Hope Comprehensive Cancer Center Duarte

\section{James Root}

Memorial Sloan-Kettering Cancer Center Inpatient Hospital and Main Campus: Memorial Sloan Kettering Cancer Center

\section{Brent Small}


University of South Florida

\section{Andrew Saykin}

Indiana University School of Medicine

danielle Tometich

Moffitt Cancer Center

Kathleen VanDyk

UCLA Health System: University of California Los Angeles Health System

Jeanne Mandelblatt

Georgetown Lombardi Comprehensive Cancer Center

\section{Research Article}

Keywords: medical care disruptions, COVID, cancer survivors, breast cancer, older adults

Posted Date: April 14th, 2021

DOl: https://doi.org/10.21203/rs.3.rs-416077/v1

License: (c) (i) This work is licensed under a Creative Commons Attribution 4.0 International License. Read Full License 


\section{Abstract}

Purpose

Older cancer survivors required medical care during the COVID-19 pandemic despite infection risks, but there are limited data on medical care in this age group.

Methods. We evaluated care disruptions in a longitudinal cohort of non-metastatic breast cancer survivors ages $60-98$ from five US regions $(n=321)$. Survivors completed a web-based or telephone survey from May 27, 2020 to September 11, 2020. Care disruptions included self-reported interruptions in ability to see doctors, receive treatment or supportive therapies, or fill prescriptions. Logistic regression models evaluated bivariate and multivariate associations between care disruptions and education, medical, psychosocial and COVID-19-related factors. Multivariate models included age, county COVID-19 rates, comorbidity and post-diagnosis time.

Results. There was a high response rate $(n=262,81.6 \%)$. Survivors were 32.2 months post-diagnosis (SD 17.5 , range $4-73$ ). Nearly half (48\%) reported a medical disruption. The unadjusted odds of care disruptions were significantly higher with more education (OR 1.23 per one-year increase, $95 \% \mathrm{Cl} 1.09$ $1.39, \mathrm{p}=0.001$ ) and greater depression (OR 1.04 per one-point increase in CES-D score, $\mathrm{Cl} 1.003-1.08$, $\mathrm{p}=0.033$ ); tangible support decreased the odds of disruptions (OR 0.99, 95\% Cl 0.97-0.99 per one-point increase, $p=0.012$ ). There was a trend for associations between disruptions and comorbidity (unadjusted OR 1.13 per 1 added comorbidity, 95\% Cl 0.99-1.29, $p=0.07$ ). Adjusting for covariates, only higher education $(p=0.001)$ and tangible social support $(p=0.006)$ remained significantly associated with having care disruptions.

Conclusions. Older breast cancer survivors reported high rates of medical care disruptions during the COVID-19 pandemic and psychosocial factors were associated with care disruptions.

\section{Full Text}

Due to technical limitations, full-text HTML conversion of this manuscript could not be completed. However, the manuscript can be downloaded and accessed as a PDF.

\section{Figures}




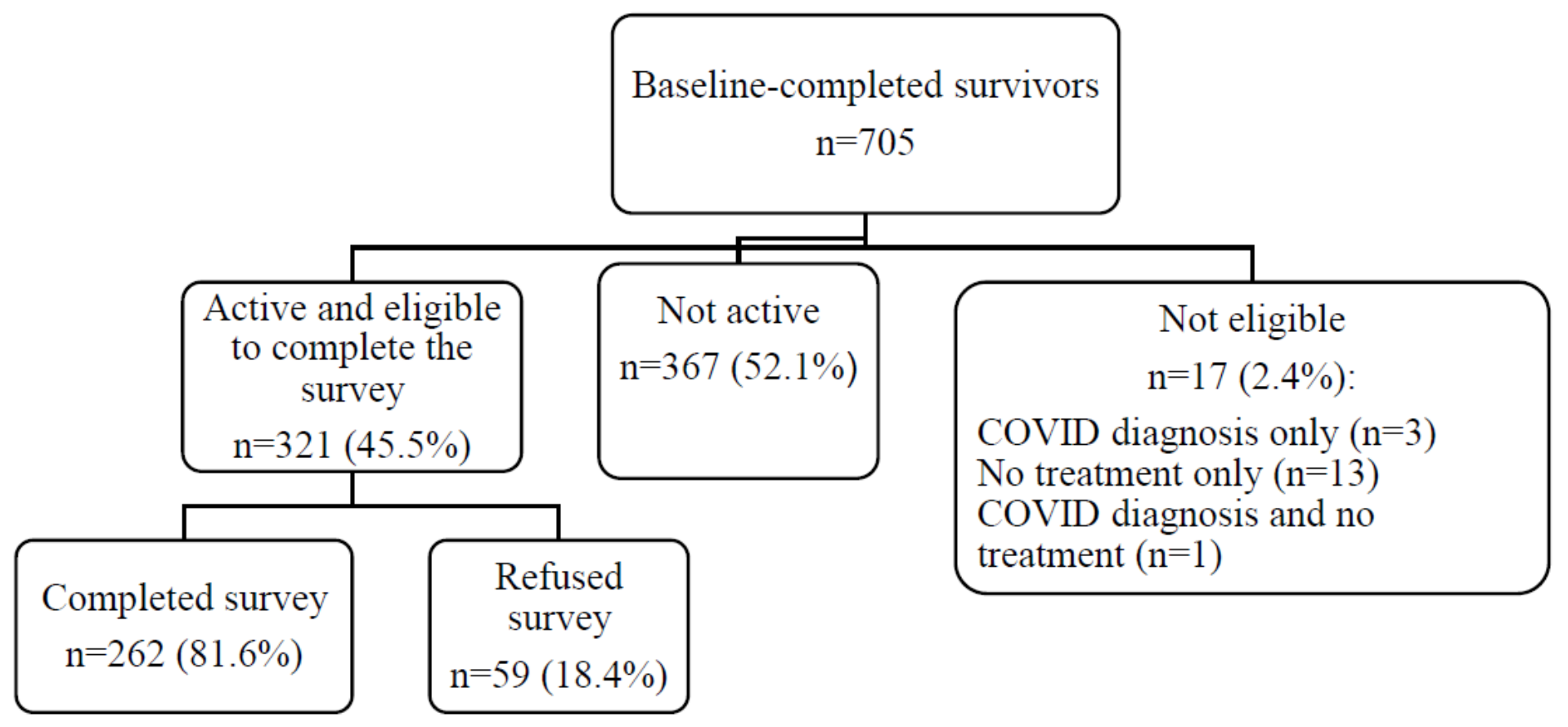

\section{Figure 1}

A sample for evaluation of medical disruptions in older breast cancer survivors. Participants were excluded if they were not active (i.e. had completed the study, dropped out, or deceased) since the start of survey data collection. The percentage who completed and refused was calculated among those active and eligible to complete the survey. Eligibility for completing the survey included no COVID-19 diagnosis and receiving treatment. 